\title{
Histopathology of Kidney In Mice (Mus musculus L) Indicated By Pre-Diabetes Mellitus Type 2 (Pre- Type 2 DM) With a variation of Yeast Treatment
}

\author{
Rudiana Agustin \\ Department of Chemistry \\ Universitas Negeri Surabaya \\ Surabaya, Indonesia \\ rudianaagustini@unesa.ac.id
}

\author{
Erlix Rakhmad Purnama \\ Department of Chemistry \\ Universitas Negeri Surabaya \\ Surabaya, Indonesia
}

\author{
Agus Widodo \\ Department of Chemistry \\ Universitas Negeri Surabaya \\ Surabaya, Indonesia
}

\begin{abstract}
A kidney is an organ that has many roles to survive. This organ can be damaged by the type 2 diabetes mellitus which is marked by high glucose in the blood. Histological studies of kidney tissue in mice (Mus musculus L.) shown by type 2 pre-Diabetes Mellitus with variations in yeast treatment have been carried out. This study uses variations in the treatment of yeast planted in red rice (red yeast) and yeast extract produced by enzymatic hydrolysis (YHE-red rice) as a comparison. Mice as the experimental animals were induced obesity-using a high-fat and fructose diet, so they showed symptoms of Pre-DM type 2 and were then treated with red yeast rice and red YHE-rice. This study used a comparison of DM mice and treated mice with glibenclamide in CMC-Na $0.2 \%$ (positive control), DM mice and treated mice with CMCNa $0.2 \%$ (negative control), and non-DM mice and treated mice with $\mathrm{CMC}-\mathrm{Na} 0.2 \%$ (normal control). Observation of renal histopathology using a light microscope. Observed Parameters included cell necrosis, glomerular nephropathy performance, increasing of Bowman's space thickness, thickening of the distal and proximal tubules, thickening of the renal arteries, and leukocyte infiltmiceion. The results showed that the kidneys of type-2 DM mice and Yeast-Red Rice and Yeast Extract-Red Rice as well as mice that indicated DM and were treated with glibenclamide in $0.2 \% \mathrm{CMC}-\mathrm{Na}$ for 1 week, did not show histological differences. Kidney when compared with non-DM mice and treated with $0.2 \%$ CMC-Na (normal control), as well as mice that were indicated by DM and treated with 0.2 CMC-Na. So to find out the effect of yeast treatment on the kidney of mice indicated by type $-2 \mathrm{DM}$, it is necessary to induce obesity and treat yeast-red rice or YHE-red rice for longer periods.
\end{abstract}

Keywords-mice, pre-type 2 DM, yeast-red rice, histopathology of kidney

\section{INTRODUCTION}

A kidney is a pair of bean-shaped organs located in the dorsal left and right spine in the lumbar region. Kidney weight is estimated to be $0.5 \%$ of body weight, and its length is $\pm 10 \mathrm{~cm}$. Every minute $20-25 \%$ of blood is pumped by the heart which flows into the kidneys. Just like other organs, the kidneys play an important role in the human body. The main function of the kidneys is to filter out wastes (waste) in the body, both those from food, drugs, or toxic substances. Another function is to control the balance of body fluids and maintain proper electrolyte levels. The kidneys excrete nitrogenous metabolic waste such as ammonia, the result of protein degradation or deamination. Besides, the kidneys also function to excrete excessive substances, such as water-soluble vitamins; maintain extracellular fluid by releasing water when excessive; maintain acid and base balance, as well as endocrine function.

The kidney consists of three main parts, namely: cortex (outer part), medulla (kidney marrow), and renal pelvis (renal cavity). The renal cortex contains a lot of nephrons \pm 1 million so that the surface of the kidney's capillaries becomes large. Each nephron consists of a long Malpighi body and tubules (channels). On Malpighi's body, there is Bowman's capsule, a layer that wraps the glomerulus. The glomerulus is in the form of arterial capillaries. The tubules in the Malpighi body are proximal tubules that roll near the Bowman's capsule where there are numerous mitochondria in the cell wall. The second tubule is the distal tubule.

In the kidney, a series of filtration, re-absorption, and augmentation processes occur. Filtrasi occurs in glomerular capillaries in Bowman's capsules. In the glomerulus, there are porous capillary endothelium cells (podocytes) making it easier for the filtering process. Several factors that facilitate the filtering process are high hydraulic pressure and permeability of the glomerulus. In addition to filtering, glomerulus also occurs in the re-binding of blood cells, pieces of blood, and most of the plasma protein. Small substances dissolved in the plasma, such as glucose, amino acids, sodium, potassium, chloride, bicarbonate, other salts, and urea pass through the filter and become part of the sediment. The result of filtering in the glomerulus is a glomerular filtrate (primary urine) whose composition is similar to blood but does not contain protein. Glomerulus filtrate can still be found in amino acids, glucose, sodium, potassium, and other salts. Human urine volume is only $1 \%$ of the glomerular filtrate. Therefore, $99 \%$ of the glomerular filtrate will be actively reabsorbed in the proximal contractile tubules and the addition of residual substances and urea in the distal contour tubules. Useful substances such as glucose and amino acids are returned to the blood. 
The rest of the excess waste salt, and other ingredients in the filtrate removed in the urine. Every day the kidney tube reabsorbs more than 178 liters of water, $1200 \mathrm{~g}$ of salt and $150 \mathrm{~g}$ of glucose. Most of these substances are reabsorbed several times. After reabsorption, the tubules will produce secondary urine whose composition is very different from the primary urine. In secondary urine, substances that are still needed will not be found again. Conversely, the concentration of toxic metabolic waste products increases. in secondary urine. The substance absorbs the tubules in two ways. Sugar and amino acid permeate through diffusion events, while water through osmosis events. Water reabsorption occurs in proximal tubules and distal tubules. Augmentation is the process of adding residual substances and urea that begin to occur in the distal tubule. The composition of urine excreted through the ureter is $96 \%$ water, $1.5 \%$ salt, $2.5 \%$ urea, and the rest of other substances, such as bile pigments that function to give warm and odor to the urine. Some disorders related to urine damage, including albuminuria (urine containing albumin due to kidney disease), nephritis (inflammation of the nephron's kidney that begins glomerular inflammation), hematuria (urine containing blood), kidney failure (increased blood urea levels, a substance that should be discharged by the kidney). The part of the kidney that plays a very important role in blood filtering is glomerulus, which is to filter proteins. This function can be disrupted if glomerular damage occurs.

Excessive drug use, obesity, and metabolic disorders can interfere with kidney function. The kidney is frequently affected in systemic diseases and, in some cases, the severity of the kidney damage is a determining factor for the survival of the patient. Diabetes mellitus is the most important by its frequency. Diabetes mellitus (DM) is a chronic metabolic disorder due to the pancreas not producing insulin or the body cannot use the insulin produced effectively. Insulin is a hormone that regulates blood glucose levels. Diabetes mellitus (DM) can be divided into 2 types, namely, type $1 \mathrm{DM}$ and type 2 . Type $2 \mathrm{DM}$ is a disruption in the receptor (receiver) of the hormone insulin, in blood cells. In this condition the productivity of the insulin hormone works well, but is not supported by a sufficient quantity of receptor volume in blood cells, this condition is known as insulin resistance. The type -2 DM is known to be the most common type of DM found in the community, as many as $90 \%$ of DM cases globally. The detection of hemoglobin $\mathrm{A}_{1 \mathrm{c}}$ levels shows that 86 million people (37\% of adults over age 20 ) suffer from pre-DM and thus are at high risk of developing diabetes [1]. Type 2 diabetes is characterized by blood glucose levels $\geq 150$ $\mathrm{mg} / \mathrm{dL}$, whereas pre-DM blood glucose levels $>126<150$ $\mathrm{mg} / \mathrm{dL}$.

Several studies have revealed that type 2 DM can be reduced by consuming chromium, one of the minerals needed by the human body. Chromium in food is in the form of $\mathrm{Cr}^{3+}$ (indicating the amount of oxidation), which is stable and safe [2]. Chromium serves to help the entry of glucose in body cells. Glucose can enter the cells of the body with the help of the hormone insulin. In this process, chromium interacts with the low-molecular weight chromium (LMWCr) substance which in turn activates insulin performance (Cefalu and HU, 2004). Foods that are known to be rich in chromium include yeast. The results showed that red rice yeast can reduce blood glucose levels [3]. High glucose levels can lead to diabetic nephropathy is a loss of chronic kidney function that occurs in people with diabetes mellitus, protein in the urine due to glomerular damage [4]. Diabetes causes several changes in the body's metabolism and blood circulation. Chronic type -2 DM can cause diabetic nephropathy and lead to end-stage renal disease (ESRD) [5]. These changes damage the structure in the glomeruli known as glomerular filtration barrier (GFB)[6]. This barrier consists of three layers including endothelium, glomerular basement membrane, and epithelial podocytes. GFB is responsible for blood filtration that is very selective in entering the glomeruli of the kidneys and usually only passes through water, small molecules, and very small proteins (albumin does not pass through the whole GFB). [7]. The damage to the glomerular basement membrane allows protein in the blood to leak, causing proteinuria. Sedimentation of a large number of the mesangial matrix by protein causes positive nodules of Schiff acids called Kimmelstiel-Wilson nodules.

\section{METHOD}

1.1. The steps taken in describing the mice kidney histopathology include 1) pre-paration of test material, 2) obesity induction, treatment by giving test material, and 3) surgery and examination of mice kidneys.

\subsection{Prepamiceion Of treatment Material}

Red yeast rice prepamiceion was carried out in several stages. The initial stage was preparing of red rice flour as a raw material for yeast growth medium, with a size of 100 mesh. In the next step, rice flour is was added with distilled water in the miceio of 5: $1(\mathrm{w} / \mathrm{v})$ and heated to form a gel and then cooled.. The gel was allowed to cool and then hydrolyzed using $\alpha$-amylase and glucoamylase enzymes for 6 hours, at room tempemiceure $\left(28 \pm 5^{\circ} \mathrm{C}\right)$. The hydrolyzate formed was added with a commercial bakery yeast miceio of 5: $1(\mathrm{v} / \mathrm{w})$, then was fermented for 10 days. The fermentation results were then centrifuged at $6,000 \mathrm{rpm}$ for 15 minutes and the obtained residue is the red rice yeast and will then be used as an ingredient for the production of YHE (yeast hydrolyzate enzymatic). Yeast-Red Rice was hydrolyzed using bromelain which was carried out at $37^{\circ} \mathrm{C}$ for 24 hours. The hydrolyzate obtained was YHE which was ready to be used as test material as well.

\subsection{Induction of obesity}

Mice were adapted for 10 days by giving a commercial food and drinking every day, and the blood glucose levels were measured using a Nesco multi check. Mice were induced by obesity using a high-fat and fructose diet of $1 \mathrm{ml} /$ day for 10 days while was still given drink and the blood glucose levels were measured after 10 days. Mice that have glucose 
levels of $\geq 140 \mathrm{mg} / \mathrm{dL}$ were declared indicated pre DM type 2 and subsequently, each treatment would be given.

\subsection{The treatment of mice uses test material}

The test material in this study is yeast red rice and yeast which have been enzymatically hydrolyzed (YHE). Positive, negative and normal controls are used as a comparison. Table 1 shows the formulation of the test material used in this study.

TABLE I. FORMULATION OF TEST MATERIAL

\begin{tabular}{ll}
\hline Treatment Group & Formulation \\
\hline Red rice Yeast & Giving red rice \\
& yeast $1 \mathrm{~mL} / \mathrm{per}$ \\
& day \\
& Giving YHE red \\
Red rice YHE & rice $1 \mathrm{~mL} / \mathrm{per}$ day \\
Glibenclamide (Positive Control) & Control \\
& glibenclamide, \\
& made diabetes and \\
& given \\
& glibenclamide $(0.9$ \\
& mg / 200 g bb \\
mice) in Na-CMC & \\
& $0.2 \%$ \\
Control \\
diabetes, made \\
diabetes and only \\
given $0.2 \%$ Na- \\
CMC. \\
Non-diabetes, was \\
given $0.2 \%$ Na- \\
CMC. \\
\hline Normal Control
\end{tabular}

Test material was given to male mice (Mus musculus L.) DDW strain aged 6 weeks, body weight 25-30 grams orally at a dose of $1 \mathrm{~mL} /$ day for 10 days.

\subsection{Surgery and Observation of kidney histology}

Mice that had been treated for 10 days are dissected and their kidneys were taken. The kidneys were stored in a physiological solution, put in a bouin's solution. The next step is to make histopathological prepamiceions from the kidneys using the paraffin method and staining hematoxylin and eosin. The prepamiceions were observed using a $400 \mathrm{X}$ magnification light microscope with observations of five sub fields of view. The parameters observed included cell necrosis, glomerular nephropathy, increased thickness of Bowman's space, thickening of the distal and proximal tubules, thickening of the renal arteries, and leukocyte infiltmiceion.

\section{RESULT AND DISCUSSION}

DM is a metabolic disorder that affects life in the world leading to hyperglycemia [8]. This disorder is divided into 2, namely DM type 1 and DM type 2. DM type 2 is a chronic metabolic disorder due to the body cannot use the insulin that is produced effectively, which is a hormone that regulates blood glucose levels.

The research carried out aims to provide a histological picture of the kidney of mice that are indicated pre-DM type 2 using a variety of red rice yeast treatment. The research that has been carried out begins with the preparation of test materials in the form of red yeast-rice and red rice YHE as a comparison, in addition to that glibenclamide + CMC-Na (positive control), commercial feed + CMC-Na (normal control), and DM + CMC -Na (negative control). The results of the analysis of the chemical composition of yeast-red rice and YHE-red rice are presented in Table 1.

TABLE II. CHEMICAL COMPOSITION OF YEAST-RED RICE AND YHERED RICE AS A TEST MATERIAL

\begin{tabular}{lllllll}
\hline $\begin{array}{l}\text { Test } \\
\text { Material }\end{array}$ & $\begin{array}{l}\text { Water } \\
\text { Level } \\
\text { (\%) }\end{array}$ & $\mathbf{C r}^{3+}$ & $\mathbf{C r}^{6^{+}}$ & $\begin{array}{l}\% \\
\text { protein }\end{array}$ & $\begin{array}{l}\text { \% } \\
\text { crude } \\
\text { fiber }\end{array}$ & $\begin{array}{l}\% \\
\text { starch }\end{array}$ \\
\hline Red & 74,06 & 103 & $49 \times$ & 38 & 5,89 & 6,643 \\
Rice & & $\mathrm{x}$ & $10^{-4}$ & & & \\
Yeast & & $10^{-4}$ & & & & \\
\hline YHE & 58,29 & $37 \times$ & $17 \times$ & 38,48 & 13,15 & 5,149 \\
Red & & $10^{-4}$ & $10^{-4}$ & & & \\
Rice & & & & & & \\
\hline
\end{tabular}

Table 1 shows that the moisture content of $\mathrm{Cr}^{3+}$, $\mathrm{Cr}^{6+}$, and crude fiber of the two test materials was very different. Several studies have revealed that type -2 DM can be reduced by consuming chromium, one of the trace minerals needed by the human body. Chromium serves to help the entry of glucose in body cells. Glucose enter to the body cells with the helping of the insulin hormone. If the amount of insulin in a person's body is insufficient or if the body's cells do not respond to insulin, there will be a buildup of glucose in the blood (hyperglycemia).

Preparation of mice as experimental animals was also carried out with the stages of adaptation, then induction of obesity using a high-fat and fructose diet for 10 days and blood glucose levels were measured. Mice that showed symptoms of pre-DM type 2 marked by blood glucose levels $>140$ were selected to be treated by giving test material for 10 days. The next step is to measure the glucose level of the mice after treatment. Table 2 shows a decrease in blood glucose levels and body weight of mice after treatment with the test material. 
TABLE III. DECREASED BLOOD GLUCOSE LEVELS AND BODY WEIGHT OF MICE AFTER TREATMENT

\begin{tabular}{llll}
\hline No & Treatment & $\begin{array}{l}\text { Weight } \\
\text { loss } \\
\text { (grams) }\end{array}$ & $\begin{array}{l}\text { Decreased } \\
\text { Blood } \\
\text { Sugar Level } \\
\text { (mg / dL) }\end{array}$ \\
\hline 1 & Red Rice Yeast & 3,0 & 130 \\
\hline 2 & YHE Red Rice & 5,0 & 131 \\
\hline 3 & Glibenclamide & 7,3 & 58 \\
\hline 4 & CMC-Na & 5,0 & 90 \\
\hline 5 & $\begin{array}{l}\text { Negative } \\
\text { Control }\end{array}$ & 7,5 & 97 \\
\hline
\end{tabular}

The results of the study showed that treatment with the intake of red yeast rice and YHE (Yeast Hydrolyzate Enzymatic) on mice could reduce blood glucose levels for mice that indicated pre-DM type 2. Grouping glucose levels as follows: normal blood glucose is $100-126 \mathrm{mg} / \mathrm{dL}$, pre$\mathrm{DM}>126<150 \mathrm{mg} / \mathrm{dL}$ type $2 \mathrm{DM}$ is characterized by blood glucose levels $\geq 150 \mathrm{mg} / \mathrm{dL}$. Decreased blood glucose levels of mice treated with red rice yeast showed a decrease in blood glucose of $130 \mathrm{mg} / \mathrm{dL}$ and YHE was $131 \mathrm{mg} / \mathrm{dL}$. Decreased blood glucose levels of rats treated with red rice yeast showed a decrease in blood glucose of $130 \mathrm{mg} / \mathrm{dL}$ and YHE was $131 \mathrm{mg} / \mathrm{dL}$. Red yeast rice is yeast that grows in red rice media, while YHE is a yeast extract from enzymatic hydrolysis. Treatment with YHE or enzymatically hydrolyzed yeast shows the highest decrease and the lowest glibenclamide reduction. Crude fiber, including carbohydrates, these compounds cannot be digested by gastrointestinal enzymes, but are useful and are known to reduce the risk of diabetes millitus. Fiber can help slow down the absorption of sugar. Some studies explain that diabetics who consume a lot of fiber need less insulin than those who don't [3].

Red rice yeast is a yeast that is grown in red rice media, while YHE is a yeast extract from enzymatic hydrolysis. Treatment with YHE or enzymatically hydrolyzed yeast showed the highest decrease and the lowest glibenclamide reduction.

Kidney organs have vital functions that can experience various problems. Kidney disease is often associated with high blood pressure, diabetes mellitus (DM), and high cholesterol. Several studies have shown that high blood sugar levels is one of the triggers for kidney damage. DM can cause diabetic complications, such as nephropathy, structural abnormalities revealing hypertrophy of glomerular and tubular elements, increased thickness of the glomerular basement membrane, extracellular matrix accumulation [8].

Studies related to kidney damage can be approached in terms of its histology. The kidneys consist of functional units known as nephrons. The nephron consists of filter parts, namely the renal corpuscle and tubules. Both components are very sensitive to the process of absorbs and ion secretion. The renal tubule is divided into 3 parts, namely: the proximal tubule, the Loop Henle, and the distal tubule. This study illustration the kidney histology of mice and their parts (Figure 1).

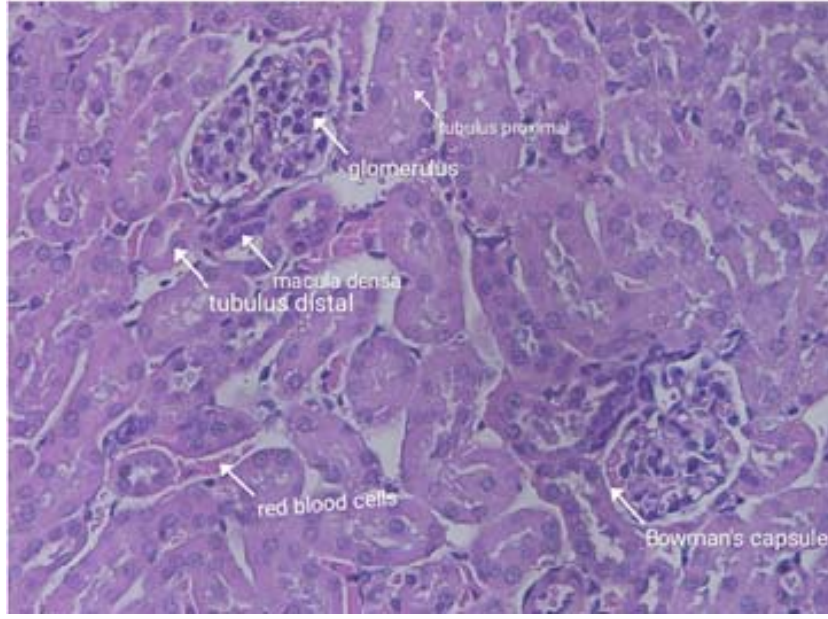

Fig. 1. Histology of the kidney of mice and their parts.

The observations of mice kidney tissue that indicated pre-DM type 2 with various treatments can be seen in Figure 2.
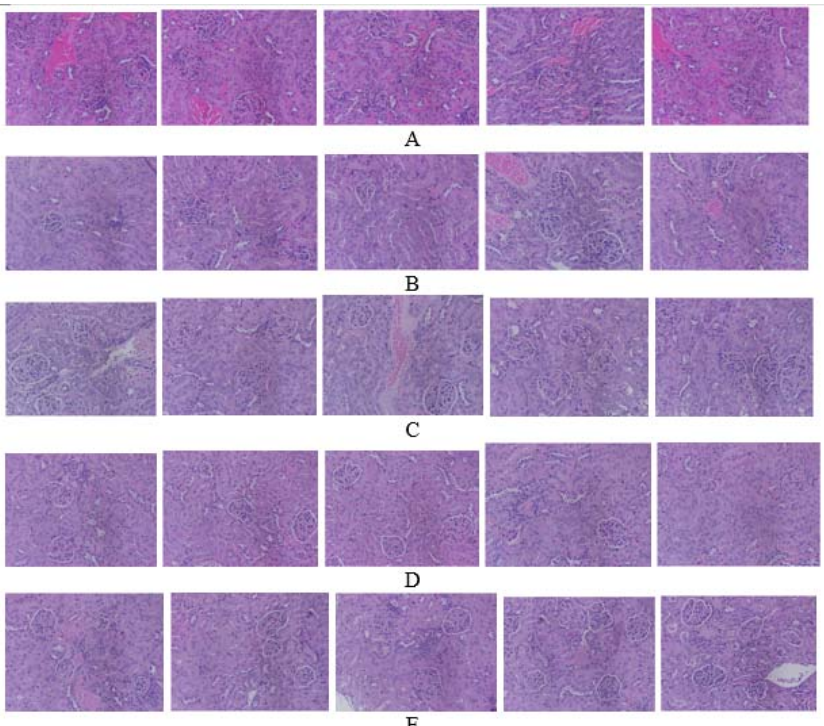

Fig. 2. Mice kidney tissue treated with: (A) yeast-red rice, (B) YHE-red rice, (C) glibenclamid and CMC-Na, (D) CMC-Na, and (E) DM and CMC-Na (Observation of a 400X light microscope, hematoxylin and eosin staining)

The very important part of the kidney is the glomerulus. This organ has the function of filtering blood. Figure 3 shows the renal glomerulus of mice in various treatments. Treatment A, B, C, D, and E were not found to be damaged. Glomerular atrophy is not visible. The basement membrane of the tubules, Bowman's capsule, and glomerular tuft can be seen as shown in Figure 3. 

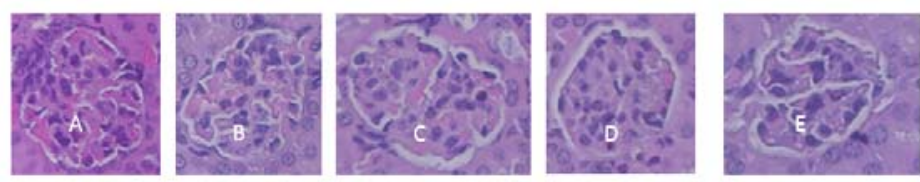

Fig. 3. Glomerulus of mice by treatment: (A) yeast-red rice, (B) YHE-red rice, (C) glibenclamid and CMC-Na, (D) CMC-Na, and (E) DM and CMC-Na (Observation of 400X light microscopy, staining of hematoxylin and eosin).

The kidney is composed of kidney cells, one of which is parenchyma cells. Figure 4 shows renal parenchyma in all treatments showing no de-generation and necrosis. Figure 4. mice parenchyma of mice by treatment: (A) yeast-red rice, (B) YHE-red rice, $(\mathrm{C})$ glibenclamide and CMC-Na, (D) CMC-Na, and (E) DM and CMC-Na (Observation of 400X light microscopy, staining of hematoxylin and eosin).

The function of the kidneys is to filter blood, take what is needed by the body and throw out unnecessary materials outside the body. Every day blood passes through the kidneys through the arteries and one of the kidney abnormalities can be shown by the presence of thickening in the artery wall which results in narrowing of the arteries or known as renal artery stenosis. Many parents show symptoms of atherosclerosis (hardening of the arteries). Renal artery stenosis eventually causes hypertension (high blood pressure) and kidney damage. Blood that reaches the kidneys is very less. The results of this study showed that all treatments given to mice did not show any thickening of the renal artery wall (Figure 5).
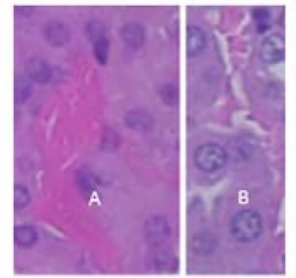

Fig. 4.
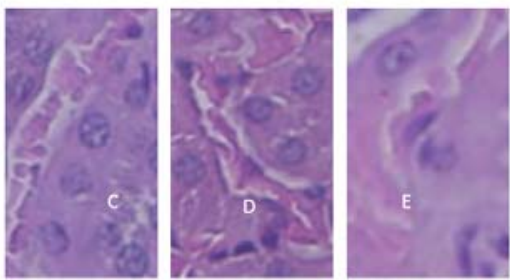

Mice kidney arteries treated with: (A) yeast-red rice, (B) YHE-red rice, (C) glibenclamide and $\mathrm{CMC}-\mathrm{Na}$, (D) CMC-Na, and (E) DM and CMC-Na (Observation of 400X light microscopy, staining of hematoxylin and eosin).

Thickening of the distal tubule plays an important role in the homeostatic process, namely: sodium chloride reabsorbs, potassium secretion, calcium and magnesium handling [9]. This tubule can experience thickening which impacts the process of reabsorption and secretion. Figure 6 shows the results of histology observations of the distal tubules for all treatments and does not show the absence of thickening.
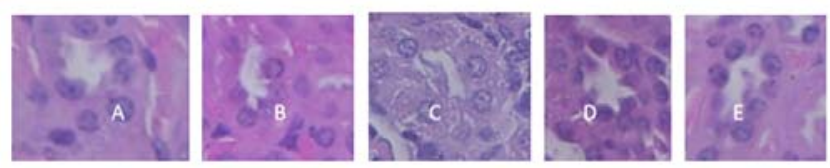

Fig. 5. Distal tubules of mice by treatment: (A) yeast-red rice, (B) YHEred rice, $(C)$ glibenclamide, and CMC-Na, (D) CMC-Na, and (E) DM and CMC- Na (400X light microscope observation, hematoxylin and eosin staining).
The other part of the kidney is the proximal tubule. se proximal tubule has a high reabsorption ability. The oportion of filtmiceed substance reabsorption in the oximal tubule is sodium and water $( \pm 66 \%)$, organic compound e.g. glucose and amino acid $(100 \%)$, potassium $( \pm 65 \%)$, urea $( \pm 50 \%)$, and phosphate $( \pm 80 \%) \quad[10]$. Interference with this tubule will affect its function in the process of reabsorption, one of which is the presence of thickening. Figure 6 shows the observations of proximal tubules in all treatments in this study that did not show any thickening.

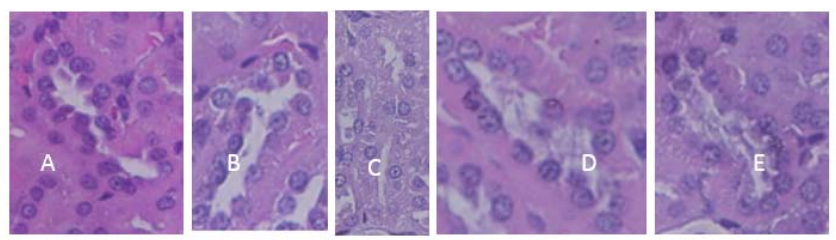

Fig. 6. Proximal tubules of mice treated: (A) yeast-red rice, (B) YHE-red rice, (C) glibenclamide and $\mathrm{CMC}-\mathrm{Na}$, (D) $\mathrm{CMC}-\mathrm{Na}$, and (E) $\mathrm{DM}$ and CMC- Na (400X light microscope observation, hematoxylin, and eosin staining).

Not all people with type 2 diabetes experience kidney dysfunction [11]. This research is preliminary. Induction of obesity using a diet high in fat and fructose for 1 week has not shown kidney damage in mice in all treatments, although glucose levels rose in mice. Then by giving treatment $\mathrm{A}, \mathrm{B}, \mathrm{C}, \mathrm{D}$, and $\mathrm{E}$ also has no effect on podocyte cells in the glomerulus. The other observation is the amount of glomerulus from each treatment as shown in Table 3.

\section{TABLE IV. THE AMOUNT OF GLUMERULUS.}

\begin{tabular}{lc}
\hline Treatment/test material & Amount of glomerulus \\
\hline Red rice Yeast & 111 \\
\hline Red rice YHE & 88 \\
\hline Glibenclamide (Positive Control) & 95 \\
\hline Normal Control (Normal Control) & 117 \\
\hline Diabetic Control (Negatif Control) & 129 \\
\hline
\end{tabular}

Data Table 3 shows that the number of the glomerulus in negative controls (DM $+\mathrm{CMC}-\mathrm{Na})$ is the highest (129). The relationship between the amount of glomerulus and DM could not be revealed in this study.

The glomerulus is a ball of capillaries surrounded by the Bowman's capsule into which urine is filtered. This part is covered by the bowman capsule, and between the parietal and visceral layers, there is a Bowman space. The results of Bowman space thickness measurements are presented in Table 4. 
TABLE V. BOWMAN SPACE THICKNESS DATA

\begin{tabular}{|c|l|l|l|l|l|}
\hline \multirow{2}{*}{ Observation } & \multicolumn{5}{l}{$\begin{array}{l}\text { Treatment / Thickness of Bowman space } \\
\text { (um) }\end{array}$} \\
\cline { 2 - 6 } & A & B & C & D & E \\
\hline 1 & 0,278 & 0,208 & 0,182 & 0,243 & 0,311 \\
\hline 2 & 0,288 & 0,473 & 0,314 & 0,103 & 0,258 \\
\hline 3 & 0,300 & 0,416 & 0,336 & 0,157 & 0,288 \\
\hline 4 & 0,273 & 0,427 & 0,457 & 0,081 & 0,474 \\
\hline 5 & 0,383 & 0,208 & 0,258 & 0,103 & 0,258 \\
\hline 6 & 0,383 & 0,310 & 0,369 & 0,093 & 0,369 \\
\hline 7 & 0,300 & 0,393 & 0,315 & 0,208 & 0,157 \\
\hline 8 & 0,288 & 0,283 & 0,109 & 0,232 & 0,220 \\
\hline 9 & 0,388 & 0,222 & 0,244 & 0,186 & 0,284 \\
\hline 10 & 0,215 & 0,208 & 0,294 & 0,387 & 0,388 \\
\hline 11 & 0,212 & 0,215 & 0,290 & 0,199 & 0,288 \\
\hline Average & 0,301 & 0,306 & 0,288 & 0,181 & 0,300 \\
\hline Note: Treatmenyyyyy \\
\hline
\end{tabular}

Note: Treatment (A) red rice yeast; (B) YHE red rice; $(\mathrm{C})$ glibenclamide + CMC-Na; (D) CMC-Na; and (D) $\mathrm{DM}+\mathrm{CMC}-\mathrm{Na}$

The data in Table 4 shows that the thickness of the Bowman space for normal control is the smallest compared to the given treatment, which is equal to $0.181 \mathrm{um}$, while other treatments have thicknesses ranging from 0.288 to $0.306 \mathrm{um}$. Thus it can be said that the treatment of red rice yeast, red rice YHE, glibenclamide + CMC-Na, and DM + $\mathrm{CMC}-\mathrm{Na}$ on mice indicated by pre-diabetes affects the thickness of Bowman space.

\section{CONCLUSION}

The kidney histology of mice indicated pre-DM type 2 after the administration of red yeast rice treatment for 10 days showed no kidney tissue damage. Likewise with other treatments (positive, normal and negative controls). These study conditions pre-DM type 2 using obesity induction, which is carried out for 10 days, therefore it is recommended that induction and treatment be carried out in a long time so that the effects on kidney histology are seen.

\section{REFERENCES}

[1] K. S. Polonsky and C. F. Burant, Type 2 Diabetes Mellitus William Textbook of Endocrinology 3rd Edition.

[2] B. E. Wilson and A. Gondy, "Effects of chromium supplementation on fasting insulin levels and lipid parameters in healthy, non-obese young subjects.," Diabetes Research and Clinical Practice, 1995.

[3] R. Agustini, I. G. M. Sanjaya and A. Widodo, "The Chemical Properties Compamiceive Of Yeast Hydrolysate Enzymatic (Yhe) From Yeast That Fermented In Rice Flour Variation," Rasayan J. Chem, vol. 12, no. 4, pp. 1839-1849, 2019.

[4] M. Ravid, H. Savin and R. Lang, "etal.Proteinuria, renal impairment, metabolic control, and blood pressure in type 2 diabetes mellitus. A 14-year follow-up report on 195 patients," Arch Intern Med, pp. 1225 $1229,1992$.

[5] V. Rigalleau, C. Lasseur, C. Perlemoine, N. Barthe, C. Raffaitin, C. Liu and H. Gin, "Estimation of Glomerular Fitration Micee in Diabetic," Diabetic Care, vol. 28, no. 4, pp. 838-843, 2005.

[6] Mora-Fernández, Domínguez-Pimentel, M. de Fuentes, J. Górriz, A Martínez-Castelao and J. Navarro-González, "Diabetic kidney disease: from physiology to therapeutics," J Physiol., vol. 592, no. 18, pp. 3997-4012, 2014.

[7] J. C. Peterson, S. Adler and J. M. Burkart, "Blood pressure control, proteinuria and the progression of renal disease," Ann Intern Med, pp. 754-762, 1995.

[8] A. L. Al-Maliki and H. A. El-Rubey, "2015The Antidiabetic Effect of Low Doses of Moringaoleifera Lam. Seeds on Streptozotocin Induced Diabetes and Diabetic Nephropathy in Male Mice," Biomed Res Int., 2015 .

[9] A. R. Subramanya and D. H. Ellison, "Distal Convoluted Tubule," Clin J Am SocNephrol, vol. 9, no. 12, pp. 2147-2163, 2014.

[10] N. P. Curthoys and O. W. Moe, "Proximal Tubule Function and Response to Acidosis," Clin J Am SocNephrol, vol. 9, no. 9, pp. 1627 1638, 2014.

[11] R. Retnakaran, A. C. Carole, I. T. Kerensa, I. A. Amanda, R. O. Rury and t. U. S. Group, "Risk Factors for Renal Dysfunction in Type 2 Diabetes," Diabetes, vol. 55, no. 6, pp. 1832-1839, 2006. 